\title{
A ROTUND REFLEXIVE SPACE HAVING A SUBSPACE OF CODIMENSION TWO WITH A DISCONTINUOUS METRIC PROJECTION
}

\author{
A. L. Brown
}

If $\mathrm{E}$ is a strictly convex (rotund) and reflexive Banach space and $\mathrm{L}$ is a closed linear subspace of $\mathrm{E}$, then $\mathrm{L}$ is a Chebyshev subspace of $\mathrm{E}$; that is, corresponding to each point $x$ in $E$ there exists in $L$ a unique point $P_{L}(x)$ that is nearest to $x$. The metric projection of $\mathrm{E}$ onto $\mathrm{L}$ is the mapping $\mathrm{P}_{\mathrm{L}}$. In [2], the authors constructed a strictly convex but nonreflexive Banach space possessing a linear subspace of codimension 2 whose metric projection is discontinuous. They conjectured that if $L$ is a closed subspace of a strictly convex reflexive space, then $P_{L}$ must be continuous. The conjecture is false even in spaces equivalent to a Hilbert space. An elegant counterexample was constructed by B. Kripke, and independently the present writer constructed a more complicated example, some features of which are more general. In both examples, the subspace $L$ is of infinite codimension, and Ivan Singer, in a private communication, asked whether an example with a subspace $L$ of codimension 2 could be constructed. Here we construct such an example by modifying our original method.

THEOREM. There exist a strictly convex, reflexive, and separable real Banach space $\mathrm{E}$ and closed linear subspaces $\mathrm{L}$ and $\mathrm{M}$, with $\mathrm{L} \subseteq \mathrm{M}$, having the properties

(1) $\mathrm{P}_{\mathrm{L}}$ is discontinuous,

(2) $\mathrm{L}$ is of codimension 2 in $\mathrm{E}$, and

(3) $\mathrm{M}$ is of codimension 1 in $\mathrm{E}$ and is a Hilbert space with respect to the norm of $\mathrm{E}$.

The construction of $\mathrm{E}$ depends upon a lemma asserting the existence of strictly convex norms with prescribed properties.

LEMMA. Let $\mathrm{F}$ be a real linear space, and let $\mathrm{p}_{1}$ and $\mathrm{p}_{2}$ be two equivalent norms on $\mathrm{F}$ with respect to which $\mathrm{F}$ is separable. If $\mathrm{p}_{1}(\mathrm{x}) \leq \mathrm{p}_{2}(\mathrm{x})$ for all $\mathrm{x} \in \mathrm{F}$ and the set $\left\{\mathrm{x} \in \mathrm{F}: \mathrm{p}_{1}(\mathrm{x})=\mathrm{p}_{2}(\mathrm{x})=1\right\}$ contains no nondegenerate line segmént, then there exists a strictly convex norm $\mathrm{p}$ on $\mathrm{F}$ with $\mathrm{p}_{1}(\mathrm{x}) \leq \mathrm{p}(\mathrm{x}) \leq \mathrm{p}_{2}(\mathrm{x})$ for all $\mathrm{x} \in \mathrm{F}$.

Proof. Throughout the proof, there will be a single topology on $\mathrm{F}$, the norm topology determined by $\mathrm{p}_{1}$ and $\mathrm{p}_{2}$.

Suppose that $y$ is a point of the open set $V=\left\{x \in F: p_{1}(x)<p_{2}(x)\right\}$. The first step in the proof is to show that there exists a norm $p_{y}$ between $p_{1}$ and $p_{2}$ that is 'strictly convex near y'. Replacing y by a multiple, we shall suppose that $\mathrm{p}_{1}(\mathrm{y})<1<\mathrm{p}_{2}(\mathrm{y})$. Since $\mathrm{F}$ is $\mathrm{p}_{2}$-separable, and by a well known result of J. A. Clarkson [1], there exists a strictly convex norm $q$ on $F$ that is equivalent to $p_{2}$. The norm $\mathrm{p}_{\mathrm{y}}$ will be obtained as a modification of $\mathrm{q}$.

Let $f \in F^{*}$ be a continuous linear functional on $F$ that has $p_{2}$-norm equal to 1 and attains its norm at $y$ : that is, such that $|f(x)| \leq p_{2}(x)$ for all $x \in F$, and $\mathrm{f}(\mathrm{y})=\mathrm{p}_{2}(\mathrm{y})$. Let

Received October 6, 1972.

Michigan Math. J. 21 (1974). 


$$
\mathrm{k}=\sup \left\{\mathrm{q}(\mathrm{x}) / \mathrm{p}_{2}(\mathrm{x}): \mathrm{x} \in \mathrm{F} \backslash\{0\}\right\} \quad \text { and } \quad \theta=\frac{1}{2 \mathrm{k}}\left(1-\frac{1}{\mathrm{p}_{2}(\mathrm{y})}\right)
$$

Define $\mathrm{q}_{\mathrm{y}}$ on $\mathrm{F}$ by

$$
\mathrm{q}_{\mathrm{y}}(\mathrm{x})=\mathrm{q}_{\mathrm{y}}\left(\frac{\mathrm{f}(\mathrm{x})}{\mathrm{f}(\mathrm{y})} \mathrm{y}+\left(\mathrm{x}-\frac{\mathrm{f}(\mathrm{x})}{\mathrm{f}(\mathrm{y})} \mathrm{y}\right)\right)=\left(\left(\frac{\mathrm{f}(\mathrm{x})}{\mathrm{f}(\mathrm{y})}\right)^{2}+\theta^{2} \mathrm{q}\left(\mathrm{x}-\frac{\mathrm{f}(\mathrm{x})}{\mathrm{f}(\mathrm{y})} \mathrm{y}\right)^{2}\right)^{1 / 2}
$$

Then (i) $\mathrm{q}_{\mathrm{y}}(\mathrm{y})=1$, (ii) $\mathrm{q}_{\mathrm{y}}$ is a strictly convex norm on $\mathrm{F}$, and (iii) $\mathrm{q}_{\mathrm{y}}(\mathrm{x}) \leq \mathrm{p}_{2}(\mathrm{x})$ for all $x \in F$. To prove (iii), we use the properties of $f$ to obtain the inequalities

$$
\begin{aligned}
q_{y}(x) & \leq\left|\frac{f(x)}{f(y)}\right| q_{y}(y)+q_{y}\left(x-\frac{f(x)}{f(y)} y\right) \leq\left|\frac{f(x)}{f(y)}\right|+\theta\left(q(x)+\left|\frac{f(x)}{f(y)}\right| q(y)\right) \\
& \leq p_{2}(x)\left(\frac{1}{p_{2}(y)}+2 \theta k\right) \leq p_{2}(x) .
\end{aligned}
$$

Now let $p_{y}=q_{y} \vee p_{1}$. Then $p_{1}(x) \leq p_{y}(x) \leq p_{2}(x)$ for all $x \in F$, so that $p_{y}$ is a norm equivalent to $p_{1}$ and $p_{2}$. Furthermore, $p_{y}(y)=q_{y}(y)$. The norms $p_{1}, p_{2}, p_{y}$ are all continuous in the topology of $\mathrm{F}$, and therefore the set

$$
\mathrm{V}_{\mathrm{y}}=\left\{\mathrm{x} \in \mathrm{F}: \mathrm{p}_{1}(\mathrm{x})<\mathrm{p}_{\mathrm{y}}(\mathrm{x})<\mathrm{p}_{2}(\mathrm{x})\right\}
$$

is an open subset of $F$ containing $y$. If $x \in V_{y}$, then $p_{y}(x)=q_{y}(x)$.

The set $\mathrm{V}$ is an open subset of the separable metric space $\mathrm{F}$. It thus has a countable base for its topology, and therefore it is a Lindelöf space-that is, every open cover has a countable subcover. Therefore there exists a sequence $(x(n))_{n \geq 1}$ such that $V=\bigcup_{n=1}^{\infty} V_{x(n)}$. Define $p$ by

$$
\mathrm{p}(\mathrm{x})=\sum_{\mathrm{n}=1}^{\infty} \frac{1}{2^{\mathrm{n}}} \mathrm{p}_{\mathrm{x}(\mathrm{n})}(\mathrm{x})
$$

Then $\mathrm{p}$ is a norm on $\mathrm{F}$, and it satisfies the conditions of the lemma. Suppose, to the contrary, that $\mathrm{p}$ is not strictly convex. Then the set $\{\mathrm{x}: \mathrm{p}(\mathrm{x})=1\}$ contains a nondegenerate line segment. The norms $p_{1}, p_{2}$, and $p$ coincide on $F \backslash V$, and therefore, by the condition of the lemma, the line segment must intersect $V$. It now follows that, for some $m$, the set $v_{x}(m) \cap\{x: p(x)=1\}$ contains a nondegenerate line segment, $[\mathrm{y}, \mathrm{z}]$ say. Then, by the equality of $\mathrm{p}_{\mathrm{x}}(\mathrm{m})$ and $\mathrm{q}_{\mathrm{x}}(\mathrm{m})$ on $\mathrm{V}_{\mathrm{x}}(\mathrm{m})$ and by the strict convexity of $\mathrm{q}_{\mathrm{x}}(\mathrm{m})$,

$$
\begin{aligned}
1 & =p\left(\frac{1}{2}(y+z)\right)=\frac{1}{2^{m}} q_{x(m)}\left(\frac{1}{2}(y+z)\right)+\sum_{n \neq m} \frac{1}{2^{n}} p_{x(n)}\left(\frac{1}{2}(y+z)\right) \\
& <\frac{1}{2^{m}}\left(\frac{1}{2} q_{x(m)}(y)+\frac{1}{2} q_{x(m)}(z)\right)+\sum_{n \neq m} \frac{1}{2^{n}}\left(\frac{1}{2} p_{x(n)}(y)+\frac{1}{2} p_{x(n)}(z)\right)=1,
\end{aligned}
$$

which is a contradiction. This completes the proof of the lemma.

The construction of an example. Let $\mathrm{E}$ be the space $\ell^{2}$ of real sequences, 


$$
\mathrm{E}=\left\{\mathrm{x}=\left(\xi_{\mathrm{k}}\right)_{\mathrm{k} \geq 1}: \sum_{\mathrm{k}=1}^{\infty} \xi_{\mathrm{k}}^{2}<\infty\right\}
$$

and let $\mathrm{e}_{1}, \mathrm{e}_{2}, \cdots$ be the standard basis. Let $\mathrm{M}=\left\{\left(\xi_{\mathrm{k}}\right) \in \mathrm{E}: \xi_{1}=0\right\}$. It will be notationally convenient to write $M=M_{2}$. For $k=3,4, \cdots$, let $M_{k}=\operatorname{sp}\left\{e_{1}, e_{k}\right\}$. We shall obtain an example satisfying the statement of the theorem, by giving $\mathrm{E}$ a suitable norm $q$ equivalent to the $\ell^{2}$-norm. Throughout the discussion, the topology on $\mathrm{E}$ is that of the $\ell^{2}$-norm. In the first place, we shall define the norm $\mathrm{q}$ on the subspaces $\mathrm{M}_{\mathrm{k}}(\mathrm{k}=2,3, \cdots)$, and we shall then invoke the lemma to obtain an extension to the whole of $\mathrm{E}$.

For $0 \leq \mathrm{t} \leq 1 / 3$

$$
1+\frac{1}{2} \mathrm{t} \leq(1+\mathrm{t})^{1-\mathrm{t}} \leq 1+\mathrm{t}
$$

Therefore we can inductively define positive real sequences $(\delta(\mathrm{k})),(\mathrm{p}(\mathrm{k})),(\alpha(\mathrm{k}))$, ' $(\lambda(\mathrm{k}))(\mathrm{k}=3,4, \cdots)$ by

$$
\delta(3)=1 / 8, \quad p(3)=16,
$$

and, for $\mathrm{k}=3,4, \cdots$,

$$
\begin{gathered}
\alpha(\mathrm{k})=\mathrm{p}(\mathrm{k})^{-1 / \mathrm{p}(\mathrm{k})}, \\
\lambda(\mathrm{k})=\left(1+\frac{1}{\mathrm{p}(\mathrm{k})}\right)^{-1+1 / \mathrm{p}(\mathrm{k})}, \\
\delta(\mathrm{k}+1)=\frac{1}{4} \delta(\mathrm{k}) \mathrm{p}(\mathrm{k})\left(\frac{1}{\lambda(\mathrm{k})}-1\right), \\
\mathrm{p}(\mathrm{k}+1)=\delta(\mathrm{k}+1)^{-\mathrm{p}(\mathrm{k})} .
\end{gathered}
$$

We also put $q(k)=p(k) /(p(k)-1)$.

It follows that

$$
\delta(\mathrm{k}+1) \leq \frac{1}{4} \delta(\mathrm{k}) \quad \text { and } \quad \mathrm{p}(\mathrm{k}) \leq \mathrm{p}(\mathrm{k}+1)
$$

Therefore the sequences $(\mathrm{p}(\mathrm{k})),(\alpha(\mathrm{k}))$, and $(\lambda(\mathrm{k}))$ are increasing and $(\delta(\mathrm{k}))$ is decreasing, with

$$
\mathrm{p}(\mathrm{k}) \rightarrow \infty, \quad \alpha(\mathrm{k}) \rightarrow 1, \quad \delta(\mathrm{k}) \rightarrow 0, \quad \mathrm{p}(\mathrm{k}) \delta(\mathrm{k}) \rightarrow \infty \quad \text { as } \mathrm{k} \rightarrow \infty .
$$

Furthermore

$$
\frac{1}{2}<\alpha(\mathrm{k}), \quad \frac{\delta(\mathrm{k})}{\alpha(\mathrm{k})} \leq \frac{1}{4}, \quad 2 \leq \mathrm{p}(\mathrm{k}) \delta(\mathrm{k}), \quad \sum_{\mathrm{k}=3}^{\infty}\left(\frac{\delta(\mathrm{k})}{\alpha(\mathrm{k})}\right)^{2} \leq \frac{1}{15},
$$

and, since $1 / \mathrm{p}(\mathrm{k}) \leq 1 / \mathrm{p}(3) \leq 1 / 3$

$$
\lambda(\mathrm{k}) \leq\left(1+\frac{1}{2 \mathrm{p}(\mathrm{k})}\right)^{-1}<1
$$


Now for $\mathrm{k}=3,4, \cdots$ put $\mathrm{x}_{\mathrm{k}}=\mathrm{e}_{1}+\delta(\mathrm{k}) \mathrm{e}_{2}$ and $\mathrm{y}_{\mathrm{k}}=\delta(\mathrm{k}) \mathrm{e}_{2}+\alpha(\mathrm{k}) \mathrm{e}_{\mathrm{k}}$, and let $\mathrm{L}$ be the closed linear hull of $\left\{\mathrm{y}_{\mathrm{k}}: \mathrm{k}=3,4, \cdots\right\}$.

For $\mathrm{k}=2,3, \cdots$ define seminorms $\mathrm{p}_{\mathrm{k}}$ on $\mathrm{E}$ by

$$
\begin{gathered}
\mathrm{p}_{2}(\mathrm{x})=\left(\sum_{\mathrm{k}=2}^{\infty} \xi_{\mathrm{k}}^{2}\right)^{1 / 2}, \\
\mathrm{p}_{\mathrm{k}}(\mathrm{x})=\left(\left|\xi_{1}\right|^{\mathrm{p}(\mathrm{k})}+\left|\xi_{\mathrm{k}}\right|^{\mathrm{p}(\mathrm{k})}\right)^{\mathrm{l} / \mathrm{p}(\mathrm{k})} \quad(\mathrm{k}=3,4, \cdots),
\end{gathered}
$$

where $\mathrm{x}=\left(\xi_{\mathrm{k}}\right) \in \mathrm{E}$. Thus the restriction of $\mathrm{p}_{2}$ to $\mathrm{M}_{2}$ is the $\ell^{2}$-norm, and the restriction of $p_{k}$ to $M_{k}(k=3,4, \cdots)$ is the $l p(k)$-norm on $M_{k}$. These norms are strictly convex, and for all $\mathrm{k}$ and $\mathrm{m}$, the seminorms $\mathrm{p}_{\mathrm{k}}$ and $\mathrm{p}_{\mathrm{m}}$ coincide on $\mathrm{M}_{\mathrm{k}} \cap \mathrm{M}_{\mathrm{m}}$.

Linear functionals $\mathrm{f}_{\mathrm{k}}(\mathrm{k}=3,4, \cdots)$ and a strictly convex norm $\mathrm{q}$ will be defined on $\mathrm{E}$ so that they have the following properties: for $\mathrm{k}=2,3, \cdots$,

$$
\begin{array}{ll}
q(x)=p_{k}(x) & \text { for all } x \in M_{k} \\
q(x) \geq p_{k}(x) & \text { for all } x \in E
\end{array}
$$

and for $\mathrm{k}=3,4, \cdots$,

$$
\begin{gathered}
q(x) \geq\left|f_{k}(x)\right| \quad \text { for all } x \in E \\
f_{k}(x)=0 \quad \text { for all } x \in L \\
f_{k}\left(x_{k}-y_{k}\right)=p_{k}\left(x_{k}-y_{k}\right)
\end{gathered}
$$

Suppose that such $q$ and $f_{k}$ have been constructed. Then, writing $P_{L}$ for the metric projection onto $L$ associated with the norm $q$, we deduce from (11), (12), and (13) that $\mathrm{P}_{\mathrm{L}}\left(\mathrm{x}_{\mathrm{k}}\right)=\mathrm{y}_{\mathrm{k}}$. However, by (10) $(\mathrm{k} \geq 3)$ and the definition of $\mathrm{p}_{\mathrm{k}}$ we see that $\mathrm{P}_{\mathrm{L}}\left(\mathrm{e}_{1}\right)=0$. Therefore, by $(6), \mathrm{P}_{\mathrm{L}}$ is discontinuous at $\mathrm{e}_{1}$.

The $\ell^{\mathrm{p}(\mathrm{k})}$-norms are smooth, and therefore the linear functional $\mathrm{f}_{\mathrm{k}}$ is determined on $\mathrm{M}_{\mathrm{k}}$ by (9), (11), and (13), and then upon $\mathrm{E}$ by (12). Let $\mathrm{f}_{\mathrm{k}}(\mathrm{k}=3,4, \cdots)$ be defined by

$$
\mathrm{f}_{\mathrm{k}}(\mathrm{x})=\lambda(\mathrm{k}) \xi_{1}+\frac{\lambda(\mathrm{k})}{\mathrm{p}(\mathrm{k}) \delta(\mathrm{k})}\left(\xi_{2}-\sum_{\mathrm{m}=3}^{\infty} \frac{\delta(\mathrm{m})}{\alpha(\mathrm{m})} \xi_{\mathrm{m}}\right)
$$

for $\mathrm{x}=\left(\xi_{\mathrm{k}}\right) \in \mathrm{E}$. It follows from the last inequality of (7) that $\mathrm{f}_{\mathrm{k}}$ is a well-defined continuous linear functional on $E$, and we can verify that (12) and (13) are satisfied.

Next we obtain inequalities for the norms of the restrictions of the functionals $\mathrm{f}_{\mathrm{k}}(\mathrm{k}=3,4, \cdots)$ to the normed linear spaces $\mathrm{M}_{\mathrm{m}}(\mathrm{m}=2,3, \cdots)$.

There is a constant $\theta<1$ such that, for all $\mathrm{x} \in \mathrm{M}_{2}$ and $\mathrm{k}=3,4, \cdots$,

$$
\left|\mathrm{f}_{\mathrm{k}}(\mathrm{x})\right| \leq \theta \mathrm{p}_{2}(\mathrm{x})
$$

If $\mathrm{x} \in \mathrm{M}_{\mathrm{k}}$, then 


$$
\left|\mathrm{f}_{\mathrm{k}}(\mathrm{x})\right| \leq \mathrm{p}_{\mathrm{k}}(\mathrm{x}) \text {. }
$$

There exist constants $\theta_{\mathrm{k}}<1(\mathrm{k}=3,4, \cdots)$, such that if $\mathrm{x} \in \mathrm{M}_{\mathrm{m}}$ and $\mathrm{m} \neq \mathrm{k}$, then

$$
\left|\mathrm{f}_{\mathrm{k}}(\mathrm{x})\right| \leq \theta_{\mathrm{k}} \mathrm{p}_{\mathrm{m}}(\mathrm{x}) .
$$

It follows from the Schwarz inequality, (8), and the last two inequalities of (7) that (14) is satisfied with $\theta=\frac{1}{2}\left(\frac{16}{15}\right)^{1 / 2}$

If $x \in M_{m}$, then, by Hölder's inequality,

$$
\left|f_{k}(x)\right| \leq \theta(k, m) p_{m}(x),
$$

where

$$
\theta(\mathrm{k}, \mathrm{m})=\lambda(\mathrm{k})\left(1+\left(\frac{\delta(\mathrm{m})}{\mathrm{p}(\mathrm{k}) \delta(\mathrm{k}) \alpha(\mathrm{m})}\right)^{\mathrm{q}(\mathrm{m})}\right)^{1 / \mathrm{q}(\mathrm{m})}
$$

If $\mathrm{m}=\mathrm{k}$, then $\theta(\mathrm{k}, \mathrm{m})=1$, and we have (15). We shall show that (16) is satisfied with $\theta_{\mathrm{k}}=(1+4 \mathrm{p}(\mathrm{k}))(2+4 \mathrm{p}(\mathrm{k}))^{-1}$. The cases $\mathrm{m}<\mathrm{k}$ and $\mathrm{k}<\mathrm{m}$ must be considered separately. For $m>k \geq 3$ we obtain from the triangle inequality for the $\ell^{q(\mathrm{~m})}$-norm, from the first inequality of $(7)$, from the monotonicity of $(\delta(\mathrm{k}))$, and from (3) and (8) the inequalities

$$
\theta(\mathrm{k}, \mathrm{m}) \leq \lambda(\mathrm{k})\left(1+\frac{\delta(\mathrm{m})}{\alpha(\mathrm{m})} \frac{1}{\mathrm{p}(\mathrm{k}) \delta(\mathrm{k})}\right) \leq \lambda(\mathrm{k})\left(1+\frac{2 \delta(\mathrm{k}+1)}{\mathrm{p}(\mathrm{k}) \delta(\mathrm{k})}\right)=\frac{1}{2}(1+\lambda(\mathrm{k})) \leq \theta_{\mathrm{k}} .
$$

For $3 \leq \mathrm{m}<\mathrm{k}$, we use the second inequality of $(7)$, the monotonicity of $(\mathrm{p}(\mathrm{k}))$, and (8) to deduce that

$$
\begin{aligned}
\theta(\mathrm{k}, \mathrm{m}) & \leq \lambda(\mathrm{k})\left(\frac{\theta(\mathrm{k}, \mathrm{m})}{\lambda(\mathrm{k})}\right)^{\mathrm{q}(\mathrm{m})} \\
& =\lambda(\mathrm{k})\left(1+\left(\frac{\delta(\mathrm{m})}{\alpha(\mathrm{m})}\right)^{\mathrm{q}(\mathrm{m})}\left(\frac{1}{\mathrm{p}(\mathrm{k})}\right)^{\mathrm{q}(\mathrm{m})}\left(\frac{1}{\delta(\mathrm{k})^{\mathrm{p}(\mathrm{m})}}\right)^{\mathrm{q}(\mathrm{m}) / \mathrm{p}(\mathrm{m})}\right) \\
& \leq \lambda(\mathrm{k})\left(1+\frac{1}{4}\left(\frac{1}{\mathrm{p}(\mathrm{k})}\right)^{\mathrm{q}(\mathrm{m})}\left(\frac{1}{\delta(\mathrm{k})^{\mathrm{p}(\mathrm{k}-1)}}\right)^{\mathrm{q}(\mathrm{m}) / \mathrm{p}(\mathrm{m})}\right)=\lambda(\mathrm{k})\left(1+\frac{1}{4 \mathrm{p}(\mathrm{k})}\right) \leq \theta_{\mathrm{k}} .
\end{aligned}
$$

Thus (14), (15), and (16) are satisfied.

Now let $q_{1}$ be the norm on $E$ defined by

$$
\mathrm{q}_{1}(\mathrm{x})=\sup \left\{\mathrm{p}_{\mathrm{k}}(\mathrm{x}): \mathrm{k}=2,3, \cdots\right\} \cup\left\{\left|\mathrm{f}_{\mathrm{k}}(\mathrm{x})\right|: \mathrm{k}=3,4, \cdots\right\} .
$$

The inequalities (14), (15) and (16) ensure that $q_{1}$ and $p_{k}$ coincide on $M_{k}$ for $\mathrm{k}=2,3, \cdots$. Later we shall use the fact that for each $\mathrm{x} \epsilon \mathrm{E}$ the supremum in the definition of $\mathrm{q}_{1}$ is attained (because $\left|\xi_{1}\right|=\lim _{\mathrm{k} \rightarrow \infty}\left|\mathrm{f}_{\mathrm{k}}(\mathrm{x})\right|=\lim _{\mathrm{k} \rightarrow \infty} \mathrm{p}_{\mathrm{k}}(\mathrm{x})$ ).

Let $A$ be the closed convex hull of $\left\{x \in \bigcup_{k=2}^{\infty} M_{k}: q_{1}(x) \leq 1\right\}$, and let $q_{2}$ be the norm for which $A$ is the unit ball. Then $q_{2}(x) \geq q_{1}(x)$ for all $x \in E$ and $\mathrm{q}_{1}(\mathrm{x})=\mathrm{q}_{2}(\mathrm{x})$ for $\mathrm{x} \in \bigcup_{\mathrm{k}=2}^{\infty} \mathrm{M}_{\mathrm{k}}$. Clearly, $\mathrm{q}_{1}$ and $\mathrm{q}_{2}$ are equivalent norms. If it is shown that 


$$
\left\{x: q_{1}(x)=q_{2}(x)\right\}=\bigcup_{k=2}^{\infty} M_{k}
$$

then it will follow by the lemma that there exists an equivalent strictly convex norm $\mathrm{q}$ on $\mathrm{E}$ such that $\mathrm{q}(\mathrm{x}) \geq \mathrm{q}_{1}(\mathrm{x})$ for all $\mathrm{x} \in \mathrm{E}$ (from which it follows that (10) and (11) are satisfied), and such that (9) is satisfied. The proof of the theorem will then be complete. Suppose that $\mathrm{y}=\left(\eta_{\mathrm{k}}\right) \in \mathrm{A}$ and $\mathrm{q}_{\mathrm{l}}(\mathrm{y})=1$ but that $\mathrm{y} \notin \mathrm{U}_{\mathrm{k}=2}^{\infty} \mathrm{M}_{\mathrm{k}}$. Then
$0<\left|\eta_{1}\right|<1$.

There exists a functional $\mathrm{f}$ such that $\mathrm{f}(\mathrm{y})=1$,

$$
|\mathrm{f}(\mathrm{x})| \leq \mathrm{q}_{1}(\mathrm{x}) \quad \text { for all } \mathrm{x} \in \mathrm{E},
$$

and such that for some $\mathrm{k}$ and some $\theta^{\prime}<1$

$$
|\mathrm{f}(\mathrm{x})| \leq \theta^{\prime} \mathrm{p}_{\mathrm{m}}(\mathrm{x}) \quad \text { for all } \mathrm{x} \in \mathrm{M}_{\mathrm{m}} \text { if } \mathrm{m} \neq \mathrm{k}
$$

Since the supremum in the definition of $\mathrm{q}_{1}$ is attained, there must exist a $\mathrm{k}$ for which either $\left|f_{k}(y)\right|=1$ or $p_{k}(y)=1$. If $\left|f_{k}(y)\right|=1$ for some $k$, then we can take $\mathrm{f}=\mathrm{f}_{\mathrm{k}}$ and $\theta^{\prime}=\theta(\mathrm{k})$. If $\mathrm{p}_{2}(\mathrm{y})=1$, take $\mathrm{k}=2$, define $\mathrm{f}$ by

$$
\mathrm{f}(\mathrm{x})=\sum_{\mathrm{m}=2}^{\infty} \eta_{\mathrm{m}} \mathrm{x}_{\mathrm{m}}
$$

and take $\theta^{\prime}=\left(1-\eta_{l}^{2}\right)^{1 / 2}$. If $p_{k}(y)=1$ for some $k \geq 3$, then with this $k$ define $f$ by

$$
\mathrm{f}(\mathrm{x})=\operatorname{sgn} \eta_{1}\left|\eta_{1}\right|^{\mathrm{p}(\mathrm{k})-1} \xi_{1}+\operatorname{sgn} \eta_{\mathrm{k}}\left|\eta_{\mathrm{k}}\right|^{\mathrm{p}(\mathrm{k})-1} \xi_{\mathrm{k}}
$$

and take $\theta^{\prime}=\left(1-\left|\eta_{1}\right| \mathrm{p}(\mathrm{k})\right)^{\mathrm{l} / \mathrm{q}(\mathrm{k})}$.

We can now obtain a contradiction. For each $\varepsilon>0$ we can find a finite convex combination $\sum_{\mathrm{m} \geq 2} \beta_{\mathrm{m}} \mathrm{z}_{\mathrm{m}}$ with $\mathrm{z}_{\mathrm{m}} \in \mathrm{M}_{\mathrm{m}}, \mathrm{q}_{\mathrm{l}}\left(\mathrm{z}_{\mathrm{m}}\right) \leq 1$ for $\mathrm{m} \geq 2$, and $\mathrm{q}_{1}\left(\mathrm{y}-\sum_{\beta_{\mathrm{m}}} \mathrm{z}_{\mathrm{m}}\right)<\varepsilon$. Then

$$
\begin{aligned}
1 & =|\mathrm{f}(\mathrm{y})| \leq\left|\mathrm{f}\left(\mathrm{y}-\sum \beta_{\mathrm{m}} \mathrm{z}_{\mathrm{m}}\right)\right|+\left|\mathrm{f}\left(\sum \beta_{\mathrm{m}} \mathrm{z}_{\mathrm{m}}\right)\right| \\
& \leq \varepsilon+\sum_{\mathrm{m} \neq \mathrm{k}} \beta_{\mathrm{m}} \theta^{\prime}+\beta_{\mathrm{k}}=\beta_{\mathrm{k}}\left(1-\theta^{\prime}\right)+\theta^{\prime}+\varepsilon
\end{aligned}
$$

so that $\beta_{k} \geq 1-\frac{\varepsilon}{1-\theta^{\prime}}$ and

$$
\begin{aligned}
\mathrm{q}_{\mathrm{l}}\left(\mathrm{y}-\beta_{\mathrm{k}} \mathrm{z}_{\mathrm{k}}\right) & =\mathrm{q}_{\mathrm{l}}\left(\left(\mathrm{y}-\sum \beta_{\mathrm{m}} \mathrm{z}_{\mathrm{m}}\right)+\sum_{\mathrm{m} \neq \mathrm{k}} \beta_{\mathrm{m}} \mathrm{z}_{\mathrm{m}}\right) \leq \varepsilon+\sum_{\mathrm{m} \neq \mathrm{k}} \beta_{\mathrm{m}} \\
& =\varepsilon+\left(1-\beta_{\mathrm{k}}\right) \leq \varepsilon \frac{2-\theta^{\prime}}{1-\theta^{\prime}} .
\end{aligned}
$$


It now follows that $y$ is in the closure of $M_{k}$, so that it is in $M_{k}$; this is a contradiction.

\section{REFERENCES}

1. J. A. Clarkson, Uniformly convex spaces. Trans. Amer. Math. Soc. 40 (1936), 396-414.

2. R. Holmes and B. Kripke, Smoothness of approximation. Michigan Math. J. 15 (1968), 225-248.

The University, Newcastle upon Tyne NE1 7RU, England 
